\title{
Metode Vertical Electrical Sounding (VES) untuk Menduga Potensi Sumberdaya Air
}

\author{
Harjito \\ Laboratorium Hidrologi dan Kualitas Air \\ Fakultas Geografi, Universitas Gadjah Mada, Yogyakarta \\ email : jitoo_2007@yahoo.co.id
}

\begin{abstract}
Abstrak
Pada umumnya pemenuhan kebutuhan air dilakukan dengan memanfaatkan airtanah. Airtanah lebih banyak dimanfaatkan dalam pemenuhan kebutuhan domestik maupun industri karena kualitas airtanah pada umumnya lebih baik dibandingkan dengan air permukaan. Potensi airtanah untuk pemenuhan kebutuhan domestik dan industri pada umumnya sulit dihitung secara tepat karena airtanah tidak tampak dan keberadaannya sangat bergantung pada kondisi geologi. Salah satu metode pendugaan yang sering digunakan adalah metode geolistrik VES (Vertical Electrical Sounding). Metode tersebut umum digunakan karena hasilnya lebih akurat, biaya operasional yang murah, dan akuisi data yang cepat. Metode VES digunakan untuk menduga lapisan-lapisan material di bawah permukaan bumi berdasarkan sifat resistivitasnya. Nilai resistivitas ( $\rho)$ dihitung berdasarkan data arus listrik (I) dan beda potensial (V) yang diperoleh di lapangan. Data arus listrik dan beda potensial diperoleh dari injeksi arus listrik ke bawah permukaan bumi melalui pasangan elektroda arus $(C 1, C 2)$ dan elektroda potensial (P1,P2). Berdasarkan hasil pendugaan menggunakan metode VES, potensi airtanah di Kota Surakarta mempunyai volume airtanah yang tersedia besar karena akuifer terdistribusi secara luas dan seragam.Debit airtanah berdasarkan perhitungan dengan data yang tersedia dan asumsi-asumsi yang digunakan, maka debit airtanah di sebagian kota Surakarta adalah $1.208 \mathrm{~m}^{3} / \mathrm{hari}$.
\end{abstract}

Kata kunci : Vertical Electrical Sounding, sumberdaya air, akuifer

\section{PENDAHULUAN}

Air merupakan materi di alam yang sangat diperlukan manusia. Selain diperlukan untuk kebutuhan dasar seperti minum, masak, mandi, mencuci, air juga dibutuhkan dalam proses-proses industri. Pada umumnya pemenuhan kebutuhan air dilakukan dengan memanfaatkan airtanah. Airtanah lebih banyak dimanfaatkan dalam pemenuhan kebutuhan domestik maupun industri karena kualitas airtanah pada umumnya lebih baik dibandingkan dengan air permukaan. Selain itu biaya distribusi airtanah jauh lebih murah dibandingkan biaya distribusi air permukaan yang sangat tergantung pada keberadaan sungai besar dan curah hujan.

Potensi airtanah untuk pemenuhan kebutuhan domestik dan industri pada umumnya sulit dihitung secara tepat karena airtanah tidak tampak dan keberadaannya sangat bergantung pada kondisi geologi. Potensi airtanah sering diperkirakan dengan menggunakan metode-metode pendugaan untuk mendapatkan data kedalaman muka airtanah dan ketebalan akuifer. Salah satu metode pendugaan yang sering digunakan adalah metode geolistrik VES (Vertical Electrical Sounding). Metode tersebut umum digunakan karena hasilnya lebih akurat, biaya operasional yang murah, dan akuisi data yang cepat. 
Kebutuhan domestik maupun industri membutuhkan airtanah dalam volume dan debit yang besar. Saat volume airtanah yang diperlukan lebih besar dari volume airtanah yang tersedia, maka proses produksi tidak akan berjalan optimal. Jika debit airtanah yang dibutuhkan lebih besar dari debit airtanah yang tersedia maka akan timbul fenomena-fenomena yang dapat merugikan industri dan lingkungan sekitar diantaranya cone of depression, subsidensi tanah, dan intrusi air laut. Untuk menghindari munculnya fenomena-fenomena tersebut, maka analisis potensi airtanah diperlukan sebelum proses produksi dimulai.

Airtanah merupakan komponen utama dalam mendukung perikehidupan dipermukaan bumi khususnya di Kota Surakarta, merupakan salah satu kota yang membutuhkan sumberdaya air dalam jumlah yang besar. Informasi mengenai potensi airtanah baik secara kualitas maupun kuantitas sangat penting diketahui sebagai dasar dalam pemanfaatan sumberdaya air secara lestari. Kuantitas airtanah yang meliputi besarnya cadangan didalam rongga airtanah atau akuifer dan debit yang dimilikinya perlu diketahui untuk berbagai aplikasi dalam penggunaanya.

\section{Tujuan Penelitian}

Studi ini dimaksudkan untuk mendapatkan gambaran yang lebih mendalam tentang potensi sumberdaya air. Adapun tujuan-tujuan yang ingin dicapai pada penelitian ini adalah:

1. Mengetahui potensi airtanah di Kota Surakarta

2. Menghitung debit dari airtanah di Kota Surakarta

\section{METODOLOGI}

Penelitian dilakukan pada beberapa lokasi di Kota Surakarta dan posisi geografis terletak antara $7^{\circ} 31^{\prime} 22^{\prime \prime} \mathrm{LS}-7^{\circ} 35^{\prime} 43^{\prime \prime} \mathrm{LS}$ dan $110^{\circ} 46^{\prime} 06^{\prime \prime} \mathrm{BT}-110^{\circ} 52^{\prime} 16^{\prime \prime} \mathrm{BT}$

Bahan yang digunakan dalam penelitian ini adalah:

a. Bensin (bahan bakar genset)

b. Batu baterai (sumber tenaga Geoelectric compensator dan GPS)

Peralatan yang digunakan dalam penelitian ini adalah: GPS Garmin Vista, Kompas, Rollmeter dan VES Geoelectric Instrument. Metode VES digunakan untuk menduga lapisan-lapisan material di bawah permukaan bumi berdasarkan sifat resistivitasnya (Telford et al., 2004). Nilai resistivitas ( $\rho$ ) 
dihitung berdasarkan data arus listrik (I) dan beda potensial (V) yang diperoleh di lapangan (Allred et al., 2008). Data arus listrik dan beda potensial diperoleh dari injeksi arus listrik ke bawah permukaan Bumi melalui pasangan elektroda arus $(\mathrm{C} 1, \mathrm{C} 2)$ dan elektroda potensial $(\mathrm{P} 1, \mathrm{P} 2)$ (Loke, 2000).

\section{Akuisi Data}

Injeksi arus listrik dilakukan melalui susunan elektroda dalam konfigurasi Schlumberger (Gambar 1). Arus listrik mengalir dalam rangkaian yang tampak pada Gambar 1. Pasangan elektroda arus $(\mathrm{C} 1, \mathrm{C} 2)$ disusun dengan jarak yang lebih besar dibandingkan pasangan elektroda potensial (P1, P2). Jarak antar pasangan elektroda arus (AB atau L) diperbesar untuk mengukur nilai resistivitas material yang lebih dalam. Saat beda potensial mulai sulit terukur, sensitivitas alat berkurang sehingga jarak antar pasangan elektroda potensial ( $\mathrm{MN}$ atau a) harus diperbesar. Besarnya arus listrik dan beda potensial untuk masing-masing jarak elektroda arus dan elektoda potensial dicatat untuk menghitung nilai resistivitas semu dari material penyusun lokasi penelitian.

Akuisi data dilakukan di lima titik yang tersebar di Surakarta. Titik-titik ditentukan agar tersebar secara merata di seluruh formasi geologi yang berada di Surakarta. Kondisi lahan yang sudah terbangun terutama untuk bangunan permukiman, industri maupun bangunan lainya menyebabkan sulitnya menemukan tempat yang ideal untuk melakukan penetrasi dengan bentangan yang maksimal. Selain itu juga kondisi lahan yang sudah terbangun jalan menyebabkan akuisisi data geolistrik terhambat oleh keberadaan konblok dan batu-batu disekitar tempat pengukuran.

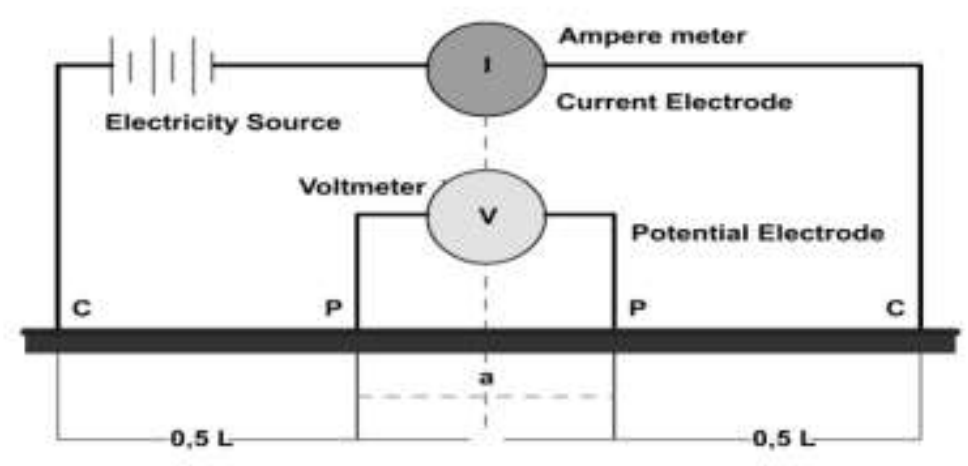

Gambar 1. Susunan elektroda dalam konfigurasi Schlumberger menunjukkan suatu rangkaian listrik 
Akuisi data dilakukan selama 2 hari yang dimulai tanggal 14 September 2013 hingga 15 September 2013. Lokasi-lokasi titik-titik akuisi data diberi nomor sesuai nomor urut akuisi data yaitu VES1 hingga VES5. Akuisi data pada titik VES1 hingga VES2 dilakukan pada tanggal 14 September 2013. Akuisi data pada titik VES3 hingga VES5 dilakukan pada tanggal 15 September 2013.

\section{Pengolahan Data}

Hasil akuisi data berupa data arus listrik dan beda potensial. Proses pengolahan data membutuhkan data resistivitas semu bukan data arus listrik (I) dan beda potensial (V). Nilai resistivitas semu ( $\rho a)$ dihitung berdasarkan data arus listrik dan beda potensial dengan menggunakan formulasi sebagai berikut:

$$
\begin{aligned}
& \mathrm{R}=\frac{V}{\mathrm{I}}, \\
& \rho \mathrm{a}=\frac{\mathrm{V}}{\mathrm{I}} \cdot \mathrm{k}, \\
& \rho \mathrm{a}=\mathrm{R} \cdot \mathrm{k} .
\end{aligned}
$$

Teknik inverse modeling melalui proses inversi dilakukan pada data resistivitas semu. Proses inversi dilakukan dengan menggunakan software IP2Win. Proses inversi dilakukan untuk mengubah nilai resistivitas semu menjadi nilai resistivitas material sebenarnya.

\section{Interpretasi Data}

Interpretasi data dilakukan dengan membandingkan nilai resistivitas hasil proses inversi dengan tabel nilai resistivitas material umum penyusun bumi. Data pada tabel bukan merupakan nilai tepat namun merupakan nilai range yang berarti material $\mathrm{x}$ dapat memiliki nilai resistivitas sebesar $\mathrm{y}$ hingga z ohm meter. Suatu nilai resistivitas dapat menunjukkan nilai resistivitas dari berbagai macam material dalam tabel sehingga diperlukan peta geologi, peta hidrogeologi, data bor, serta data pendukung lain untuk mengetahui jenis material yang pasti dari nilai resistivitas tersebut. Data pendukung yang digunakan untuk interpretasi nilai resistivitas antara lain Peta Geologi Lembar Surakarta Skala 1:100.000, Peta Hidrogeologi Lembar Yogyakarta Skala 1:250.000.

\section{Perhitungan Debit Airtanah}

Hasil interpretasi dari nilai resistivitas menunjukkan material-material penyusun daerah penelitian yang terdiri atas material akuifer dan material non akuifer. Kedalaman dari lapisan-lapisan 
akuifer dan ketebalan akuifer dapat diketahui dari interpretasi data nilai resistivitas material. Debit airtanah dihitung berdasarkan Hukum Darcy (Kodoatie, 1996), sebagai berikut:

$$
\mathrm{Q} \quad=\mathrm{K} \cdot \mathrm{I} \cdot \mathrm{A}
$$

Variabel $\mathrm{K}$ merupakan hydraulic conductivity ( $\mathrm{m} / \mathrm{hari}$ ), variable I adalah hydraulic gradient, sedangkan variable A adalah luas potongan Akuifer $\left(\mathrm{m}^{2}\right)$. Variabel hydraulic gradient dan luas permukaan akuifer diperoleh berdasarkan pemodelan tiga dimensi dari akuifer yang diidentifikasi berdasarkan data geolistrik metode VES. Pemodelan akuifer tiga dimensi dilakukan dengan menggunakan software Rockworks. Variabel hydraulic conductivity diperoleh berdasarkan data transmisivitas pemompaan (pumping transmisivity) hasil pumping test yang dilakukan di Klaten oleh Tim Laboratorium Kualitas Air pada tahun 2013. Berdasarkan Kodoatie (1996) hubungan antara transmisivitas dan hydraulic conductivity tampak pada persamaan :

$$
\mathrm{T}=\mathrm{K} \cdot \mathrm{b}
$$

Variabel $\mathrm{T}$ merupakan transmisivitas $\left(\mathrm{m}^{2} / \mathrm{hari}\right)$, Variabel $\mathrm{b}$ adalah tebal akuifer (m) yang diperoleh dari interpretasi data VES, nilai $\mathrm{K}$ atau hydraulic conductivity dapat diperoleh dengan menggunakan persamaan:

$$
\mathrm{K}=\mathrm{T} / \mathrm{b}
$$

\section{HASIL DAN PEMBAHASAN}

\section{Data Beda Potensial dan Arus Listrik}

Validasi dari data yang diperoleh dilakukan dengan ploting data beda potensial terhadap faktor geometris. Nilai beda potensial pada VES1 hingga 5 diplot pada scatter plot kemudian dilakukan analisis kecenderungan. Berdasarkan hasil analisis kecenderungan, data VES1 hingga VES5 merupakan data yang memiliki error yang rendah karena kurva kecenderungan (kurva merah) membentuk kurva eksponensial yang berarti bahwa nilai beda potensial cenderung menurun seiring dengan bertambahnya faktor geometris.

Penurunan nilai beda potensial dikarenakan penurunan sensitivitas alat akibat bertambahnya kedalaman injeksi arus listrik. Pengecualian untuk titik VES4 dan 5, kurva kecenderungan tidak menunjukkan kurva eksponensial yang berarti, data pada VES5 memiliki nilai error yang tinggi 
yaitu mencapai kurang lebih $40 \%$. Error pada data yang tinggi kemungkinan disebabkan oleh beberapa faktor antara lain tingginya kelembaban tanah dipermukaan, tingginya kandungan ion pada tanah, kadar lempung yang sangat tinggi, atau error pada alat. Data pada titik VES4 dan 5 yang memiliki error tinggi tetap dapat digunakan melalui proses synthetic curve yang dilakukan dengan menggunakan software IP2Win.

Terkait dengan data, ditemui beberapa kendala terutama pada besarnya kisaran error yang terjadi. Besaran error yang terjadi sebesar kurang dari 40\%. Sehingga perlu dilakukan smoothing dan koreksi data agar data hasil geolistrik dapat diolah dengan tingkat akurasi yang mendekati kondisi sebenarnya.Selain itu bentangan geolistrik yang dilakukan penetrasi alat memiliki bentangan yang tidak seragam. Ada yang memenuhi bentangan standart sejauh $250 \mathrm{~m}$ sampai dengan $300 \mathrm{~m}$ namun juga ada yang hanya mencapai $125 \mathrm{~m}$. Sehingga kedalaman yang dapat dapat dianalisis hanya sekitar 45 sampai 50 pada titik bentangan terpanjang, dan sekitar 15 meter untuk titik bentangan pendek.

Kondisi titik-titik penetrasi alat yang memiliki perbedaan ketinggian yang cukup besar menjadi salah satu poin penting yang harus menjadi catatan. Ketinggian yang memiliki perbedaan yang mencolok dinilai kurang baik untuk pengukuran menggunakan geolistrik. Secara teoritis geolistrik seharusnya dilakukan pada satuan bentuk lahan yang sama, sehingga hasil pengukuran geolistriknya dapat dicrossectionkan dengan titik lain dalam satu bentuk lahan yang sama. Hal ini berangkat dari asumsi bahwa bentuk lahan memiliki karakteristik relief, material, dan proses geomorfologi yang sama, sehingga dalam hal ini kodisi hidrogeologi dari suatu daerah sangat dipengaruhi oleh kondisi geomorfologinya. Konsekuensi dari hal itu jika dipaksa untuk dilakukan maka seharusnya analisis hanya bisa dilakukan pada setiap titik pengukuran. Artinya satu titik hanya bisa dianalisis sebagai satu data interpretasi yang disamakan dengan data bor. Selain itu titik pengukuran yang berada pada tiga formasi geologi yang berbeda sebenarnya juga kurang baik. Akan lebih baik jika pada setiap formasi geologi terdapat lebih dari dua titik pengukuran, sehingga dapat dilakukan cross section untuk satu formasi batuan, sehingga hasilnya lebih objektif menurut material yang sama dan karakter geomorfologi yang sama.

\section{Data Resistivitas Semu (pa)}

Nilai resistivitas semu diperoleh berdasarkan perhitungan menggunakan persamaan (1.2). Faktor geometris ditentukan dengan berdasarkan variabel jarak antar elektroda arus (C1-C2) dan variabel jarak antar elektroda potensial (P1-P2). Faktor geometris dapat langsung diketahui dengan input 
data jarak antar elektroda arus dan jarak antar elektroda potensial pada software IP2Win. Namun dalam pengukuran ini nilai resistivias langsung dihitung dilapangan menggunakan formulasi yang ada untuk melihat hasil sementara agar kontrol eror yang terjadi pada saat pengukuran dapat diperkecil.

\section{Apparent Resistivity Pseudosection (pa)}

Apparent resistivity pseudosection merupakan penampang melintang semu yang menggambarkan distribusi nilai resistivitas semu suatu titik VES terhadap titik VES lainnya dibawah permukaan bumi. Penampang melintang semu tersebut memiliki absis jarak antar titik VES satu dengan titik VES lainnya dan ordinat nilai $\mathrm{AB} / 2$ atau 1/2L. Ordinat tidak menunjukkan kedalaman sebenarnya namun menunjukkan kedalaman semu. Faktor konversi untuk mengubah kedalaman semu tersebut menjadi kedalaman sebenarnya dapat berkisar antara 0.33 hingga 0.14 .

Empat penampang melintang dibuat pada penelitian ini untuk memberikan gambaran umum susunan lapisan material bawah permukaan bumi pada lokasi penelitian. Penampang melintang 1 meliputi titik VES2-VES1- VES4. Penampang melintang 2 meliputi titik VES2-VES3. Penampang melintang 3 meliputi titik VES2-VES5. Sedangkan penampang melintang 4 meliputi titik VES3VES5. Arah aliran pada penampang melintang semu dapat diketahui melalui karakteristik perubahan warna. Perubahan warna yang tegas menunjukkan kontak material yang berbeda sedangkan perubahan warna yang gradual menunjukkan terdapatnya kandungan air pada material. Penampang melitang semu dan kemungkinan arah aliran airtanahnya tersaji pada Gambar 2a-4d. 


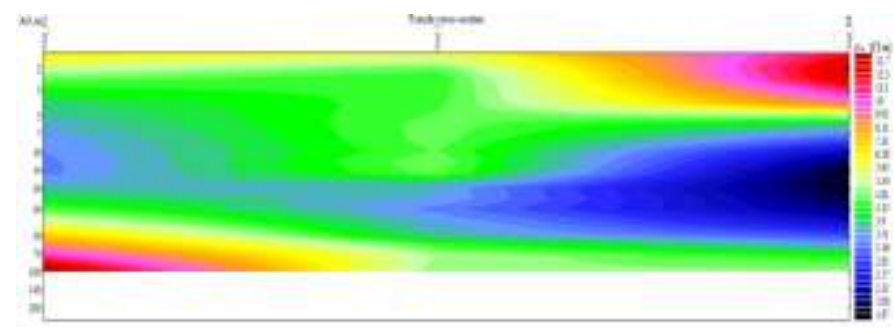

(a)

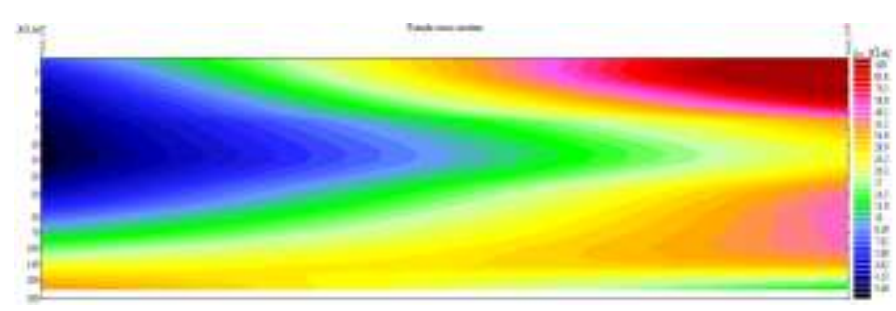

(c)

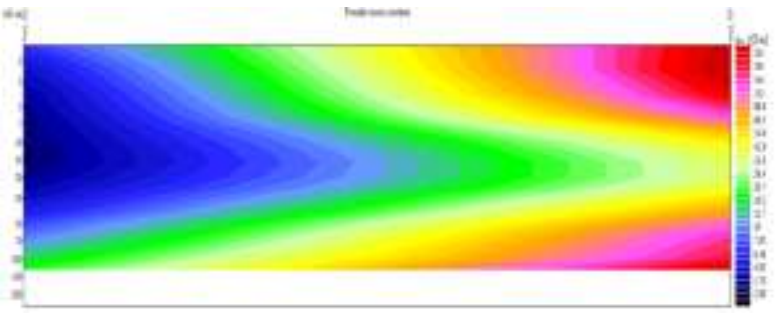

(b)

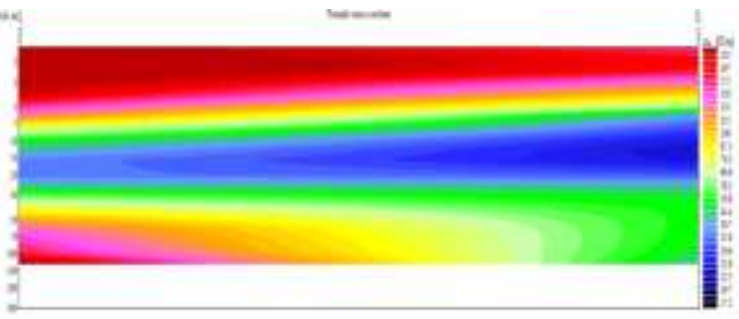

(d)

Gambar 2. Penampang melintang semu lapisan bawah permukaan Bumi (a) dari titik VES2-VES1VES4, (b) dari titik VES2-VES3, (c) dari titik VES2-VES5, dan (d) dari titik VES3-VES5

\section{Tabel Nilai Resistivitas Sebenarnya}

Proses inversi dilakukan pada nilai resitivitas semu menggunakan software IP2Win untuk mendapatkan nilai resistivitas sebenarnya. Hasil inversi adalah tabel nilai resistivitas yang mencakup informasi nilai resistivitas yang sebenarnya dan distribusinya menurut kedalaman dari permukaan Bumi. Nilai resistivitas sebenarnya merupakan nilai resistivitas yang dapat diinterpretasi karena nilai tersebut disertai dengan informasi distribusinya menurut kedalaman di bawah permukaan Bumi. Nilai resisitivitas sebenarnya berbeda dengan nilai resistivitas semu yang tidak memiliki informasi kedalaman melainkan hanya memiliki nilai $\mathrm{AB} / 2$ atau $1 / 2 \mathrm{~L}$ yang menunjukkan jarak antar pasangan elektroda arus dan potensial atau nilai kedalaman semu.

Kolom $\rho$ pada tabel nilai resistivitas memberikan informasi nilai resistivitas sebenarnya (satuan dalam $\Omega . \mathrm{m}$ ). Kolom h pada tabel memberikan informasi ketebalan lapisan (satuan dalam m) untuk masing-masing nilai resistivitas pada kolom $\rho$. Kolom d memberikan informasi kedalaman lapisan (satuan dalam $\mathrm{m}$ ) untuk masing-masing nilai resistivitas pada kolom $\rho$ terhadap permukaan Bumi (permukaan Bumi memiliki nilai kedalaman $0 \mathrm{~m}$ ). Kolom "alt" memberikan informasi kedalaman lapisan (satuan dalam $\mathrm{m}$ ) untuk masing-masing nilai resistivitas pada kolom $\rho$ terhadap titik datum 
elevasi (pada penelitian ini titik datum elevasi adalah $0 \mathrm{~m}$ ). Interpretasi dari tabel nilai resistivitas sebenarnya dilakukan dengan menggunakan Peta Geologi Lembar Surakarta Skala 1:100.000, dan Peta Hidrogeologi Lembar Yogyakarta Skala 1:250.000. Hasil dari interpretasi titik VES 5 di duga terdapat confined aquifer atau aquifer tertekan, akuifer tertekan ini akan terlihat jelas seandainya bentangan yang dilakukan lebih jauh dari 300 meter. Confined akuifer atau akuifer tertekan ini terjadi karena material lava yang bersifat kedap air berada menumpang pada lapisan batuan yang lebih permeabel. Hasil dari tabel interpretasi kemudian digambarkan pada 3a, b. dibawah ini.
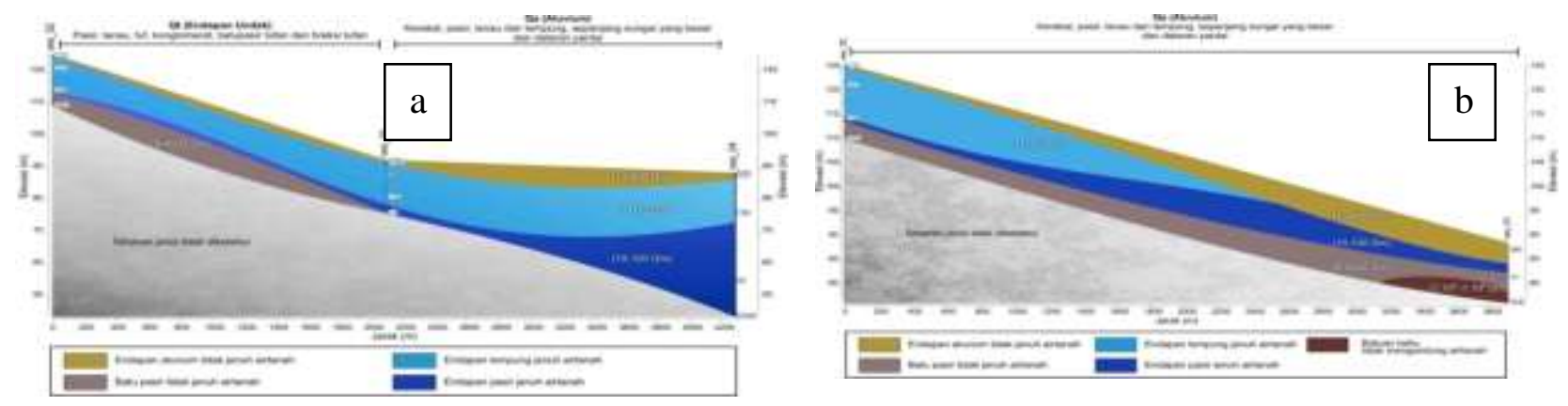

Gambar 3. Penampang melintang sebenarnya lapisan bawah permukaan Bumi (a) dari titik VES1-VES2-VES4, (b) dari titik VES2-VES3
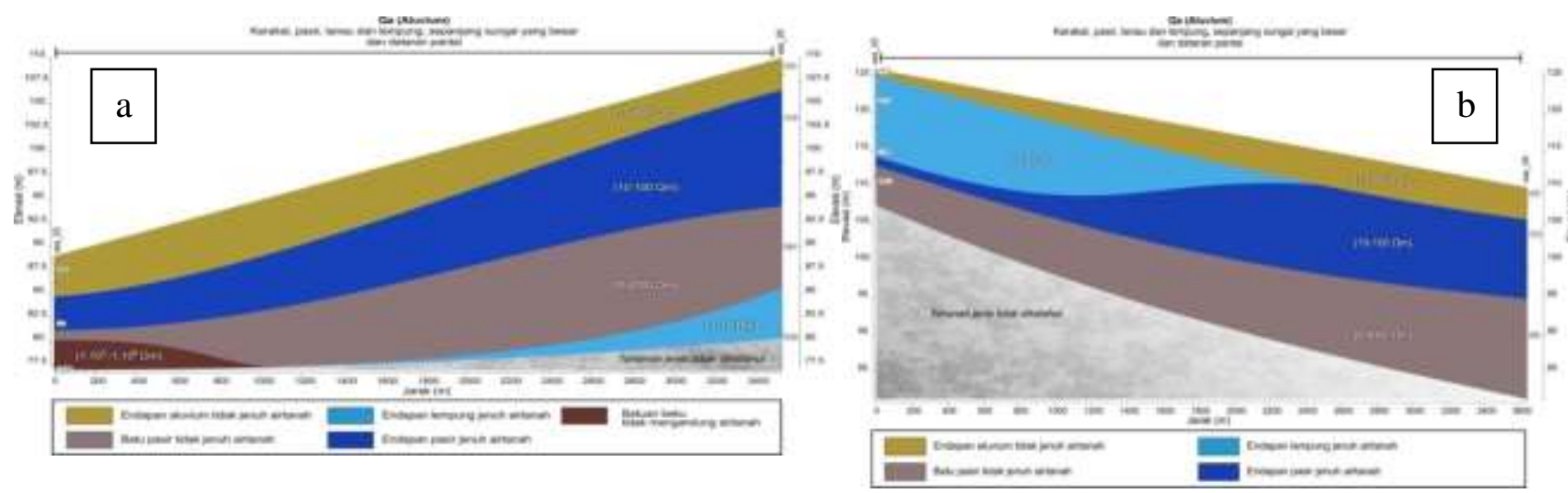

Gambar 4. Penampang melintang sebenarnya lapisan bawah permukaan Bumi (a) dari titik VES3-VES5-VES4, (b) dari titik VES2-VES5

Tampak bahwa warna biru adalah warna dimana diduga terdapat akuifer yang menyimpan cadangan airtanah. Selain itu pada penampang melintang yang lain juga digambarkan pada gambar 4a-b. 


\section{Curva VES}

Curva VES merupakan kurva yang menunjukkan hubungan antara jarak antar elektroda arus $(\mathrm{AB} / 2)$, nilai resistivitas semu ( $\rho$ a), nilai resistivitas sebenarnya $(\rho)$, serta distribusi kedalaman dan ketebalan lapisan-lapisan nilai resistivitas sebenarnya $(\rho)$. Titik-titik dan kurva merah menunjukkan hubungan antara $\mathrm{AB} / 2$ dan $\rho$. Kurva biru menunjukkan distribusi kedalaman dan ketebalan dari lapisan-lapisan nilai resistivitas sebenarnya. Curva VES dapat digunakan untuk memudahkan representasi hasil interpretasi tabel nilai resistivitas sebenarnya. Hubungan antara jenis dan susunan material bawah permukaan Bumi terhadap variabel-variabel VES akan tampak lebih mudah dipahami melalui representasi dari hasil interpretasi tabel nilai resistivitas sebenarnya pada curva VES.

\section{Kedalaman dan Tebal Akuifer}

Informasi kedalaman akuifer dan tebal akuifer dari titik-titk VES diperoleh berdasarkan interpretasi tabel nilai resistivitas sebenarnya,data kedalaman akuifer tersaji pada Tabel 1. Berdasarkan Tabel 1 warna kuning merupakan aquiclude, aquiqlude merupakan material yang terdiri dari partikel berukuran lempung. Material ini dapat menyimpan airtanah dan terkadang dimasukkan dalam klasifikasi material jenuh air. namun material ini sangat susah untuk menyalurkan airtanah dengan baik, sehingga dalam penelitian ini tidak dimasukkan dalam akuifer. Akuifer yang dihitung dan dianalisis dalam penelitian ini adalah akuifer dengan material pasir. Material pasir merupakan akuifer yang baik dan terdapat pada titik VES 3, VES 4, dan VES 5. Ketebalan material pasir sebagai akuifer adalah 12,5 m. Akuifer ini ditemukan pada kedalaman 2 meter dari atas permukaan dan ditemukan pada titik VES 5. Titik VES 5 merupakan titik dimana material alluvial menjadi material dasarnya.

Tabel 1. Kedalaman akuifer pada titik VES1 hingga VES 5

\begin{tabular}{|c|c|c|}
\hline No. & Kedalaman Akuifer $(\mathbf{m})$ & Ketebalan akuifer $(\mathbf{m})$ \\
\hline VES1 & $0-13,5$ & 13,5 \\
\hline VES2 & $1-14,5$ & 13,5 \\
\hline VES3 & $3-11,5$ & 8,5 \\
\hline VES4 & $24-44$ & 20,0 \\
\hline VES5 & $2-11$ & 9,0 \\
\hline \multicolumn{2}{|r|}{ Rataan } & $\mathbf{1 2 , 9}$ \\
\hline
\end{tabular}


Data kedalaman dan ketebalan akuifer dapat digunakan untuk mengetahui bentuk dan distribusi akuifer. Bentuk dan distribusi akuifer diketahui melalui pemodelan akuifer tiga dimensi dengan menggunakan software Rockworks. Model akuifer tiga dimensi tersaji pada Gambar 7. Pada model tersebut, material penyusun lokasi penelitian dikelompokkan menjadi 5 macam material yaitu material aluvium atas yang merupakan material non akuifer atas, material pasir yang merupakan akuifer dalam penelitian ini, material aluvium bawah, material lempung, dan terakhir adalah material batuan beku volkanik.

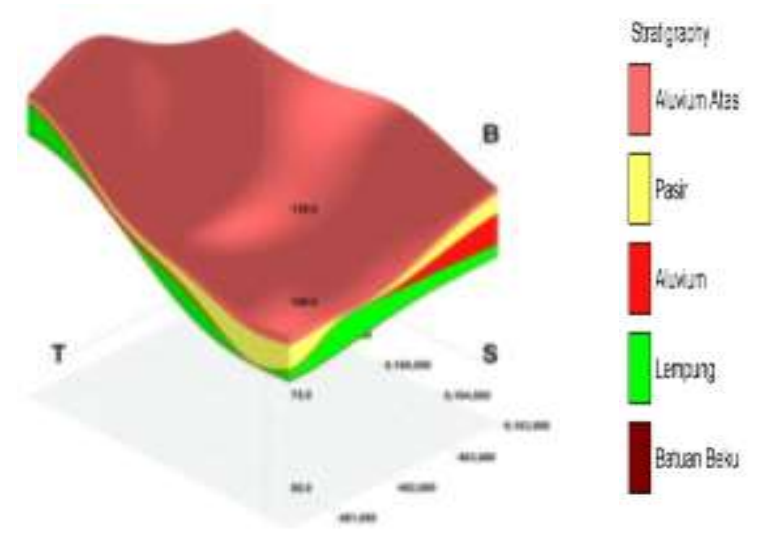

Gambar 5. Model akuifer tiga dimensi di lokasi penelitian
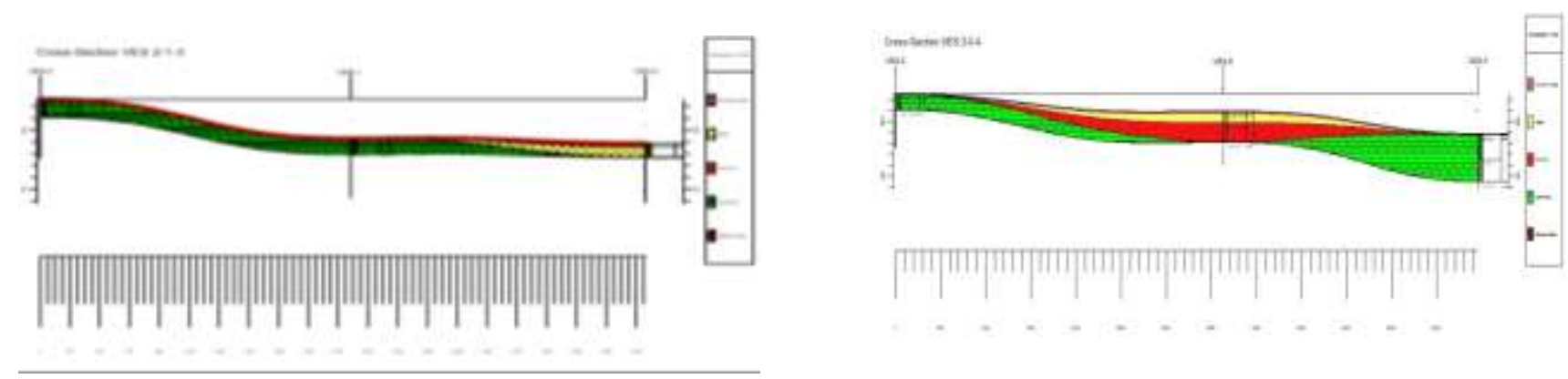

Gambar 6. Model akuifer tiga dimensi di lokasi penelitian

Dalam penelitian ini, dapat dikatakan bahwa airtanah cenderung mengalir ke arah VES 3 dan VES 4, hal ini akan nampak sekali jika kita perhatikan pada kurva 8. sehingga dalam penelitian ini analisis debit airtanah hanya dilakukan untuk titik VES 3, VES 4 dan VES 5. Adapaun VES 1 dan VES 2, analisis sulit dilakukan karena faktor-faktor teknis. Faktor-faktor teknis itu antara lain kondisi material dasar yang berbeda, kondisi bentangan yang berbeda, serta adanya batas sebuah sungai yang cukup dalam antara VES1-VES2 dengan VES3-VES5. Hal ini sangat berpengaruh, karena kita tidak mengetahui apakah sungai itu bersifat influent atau efluent terhadap kondisi 
airtanah. Hasil pemodelan tiga dimensi dapat pula kita ketahui volume dari masing-masing material penyusun stratigrafi daerah penelitian seperti yang tersaji pada Tabel 2.

Tabel 2. Volume material stratigrafi hasil interpretasi data geolistrik

\begin{tabular}{|r|l|r|}
\hline No & \multicolumn{1}{|c|}{ Stratigrafi } & Volume $\mathbf{( m}^{\mathbf{3}} \mathbf{~}$ \\
\hline 1 & Aluvium atas & 26.116 .896 \\
\hline 2 & Pasir & 51.724 .820 \\
\hline 3 & Aluvium & 77.015 .370 \\
\hline 4 & Lempung & 204.045 .609 \\
\hline 5 & Batuan Beku & 3.256 .856 \\
\hline \multicolumn{2}{|c|}{ Total } & $\mathbf{3 6 2 . 1 5 9 . 5 5 1}$ \\
\hline
\end{tabular}

\section{Debit Airtanah}

Debit airtanah di lokasi kajian dihitung dengan menggunakan Hukum Darcy (Persamaan 1.4). Variabel-variabel yang diperlukan untuk menghitung debit berdasarkan Hukum Darcy adalah hydraulic conductivity (K), hydraulic gradient (I), dan luas potongan akuifer (A). Nilai $\mathrm{K}$ atau hydraulic conductivity diperoleh dari uji pompa (pumping test) yang dilakukan oleh Laboratorium Kualitas Air Fakultas Geografi di Daerah Klaten pada tahun Hydraulic conductivity hasil uji pompa tersebut adalah 4,46 m/hari. Perhitungan hydraulic conductivity menggunakan asumsi sebagai berikut:

a. Material penyusun akuifer pada lokasi pumping test di daerah Klaten dan lokasi penelitian adalah sama, yaitu tersusun dari materil volkanik gunungapi merapi yang terdiri dari endapan piroklastika berukuran pasir.

b. Hydraulic conductivity pada lokasi pumping test di daerah Klaten dan lokasi penelitian adalah sama, yaitu termasuk di dalam pasir berukuran sedang.

Hydraulic gradient akuifer pada lokasi penelitian menggunakan data kedalaman maksimum dan minimum akuifer. Hydraulic gradient akuifer permukaan atau Ip dihitung sebagai berikut:

$$
\mathrm{I}=\Delta \mathrm{h} / \Delta \mathrm{i},
$$

kedalaman maksimum akuifer permukaan yaitu sebesar $24 \mathrm{~m}$ terdapat pada titik VES4 dan minimum sebesar 3 m pada titik VES5, maka: 


$$
\mathrm{I}_{\mathrm{p}} \quad=(24-3) / \Delta \mathrm{i}
$$

jarak titik VES3 dan VES5 adalah 2.845 m sehingga:

$$
\begin{aligned}
& \text { Ip }=(24-3) / 2.845 \\
& \text { Ip }=0,007
\end{aligned}
$$

Variabel A atau luas potongan akuifer dihitung berdasarkan dimensi akuifer. Panjang akuifer material pasir adalah $2.500 \mathrm{~m}$. Sendangkan rata-rata tebal akuifer adalah $12,5 \mathrm{~m}$. Sehingga diperoleh dimensi akuifer pada lokasi penelitian adalah dihitung sebagai berikut:

$$
\begin{array}{ll}
\text { A } & =p \cdot b \\
\text { A } & =2.500 \mathrm{~m} \cdot 12,5 \mathrm{~m} \\
\text { A } & =31.250 \mathrm{~m}^{2},
\end{array}
$$

Debit airtanah di lokasi kajian dihitung dengan subtitusi variabel-variabel yang telah dihitung diatas ke Hukum Darcy. Debit airtanah pada akuifer permukaan Q dihitung sebagai berikut:

$$
\begin{array}{ll}
\mathrm{Q} & =\mathrm{K} . \mathrm{I} . \mathrm{A} \\
\mathrm{Q} & =(4,46 \mathrm{~m} / \mathrm{hari}) \cdot(0,007) \cdot\left(31.250 \mathrm{~m}^{2}\right) \\
\mathrm{Q} & =1.028 \mathrm{~m}^{3} / \text { hari }
\end{array}
$$

\section{KESIMPULAN}

Berdasarkan hasil pendugaan menggunakan metode VES, potensi airtanah di Kota Surakarta mempunyai volume airtanah yang tersedia besar karena akuifer terdistribusi secara luas dan seragam.Debit airtanah berdasarkan perhitungan dengan data yang tersedia dan asumsi-asumsi yang digunakan, maka debit airtanah di sebagian kota Surakarta adalah $1.208 \mathrm{~m}^{3} /$ hari.

\section{DAFTAR PUSTAKA}

Allred, B.J., J.J. Daniels \& M.R. Ehsani., 2008. Handbook of Agricultural Geophysics, Boca Raton, CRC Press

Bobachev, A., 2001, Win with IP2Win: IP2Win v. 2.1, IPI_Res2, IPI_Res3 user's guide, Moscow: Department of Geophysics Geological Faculty, Moscow State University

CV. Kusumo, 2008, Laporan Hasil Pengeboran Air (ABT) di Pengkol, Semarang

Djaeni, A., 1982, Hidrogeologi Lembar Yogyakarta, Direktorat Geologi Tata Lingkungan, Bandung 
Kodoatie, R. J., 1996, Pengantar Hidrogeologi, Penerbit Andi, Yogyakarta

Lowrie, W., 2007, Fundamentals of Geophysics, 2nd Edition, Cambridge University Press, Cambridge

Loke, M.H., 2000, Electrical Imaging Survey for Environmental and Engineering Studies, diakses melalui http://www. geometrics.com pada 06 Maret 2009

Milsom, J., 2003, Field Geophysics, The Geological Field Guide Series 3rd Edition, John Wiley \& Sons, West Sussex

Roy, K.K., 2008, Potential Theory in Applied Geophysics,Springer-Verlag, Berlin 